\title{
A study of pregnancy outcome in patients with cardiac disease
}

\author{
Pradnya D. Kamble*, Amarjeet Kaur Bava
}

Department of Obstetrics and Gynecology, LTMMC and LTMGH, Sion, Mumbai, Maharashtra, India

Received: 15 October 2018

Accepted: 27 October 2018

\section{*Correspondence:}

Dr. Pradnya D. Kamble,

E-mail: pradnyakamble2791@gmail.com

Copyright: () the author(s), publisher and licensee Medip Academy. This is an open-access article distributed under the terms of the Creative Commons Attribution Non-Commercial License, which permits unrestricted non-commercial use, distribution, and reproduction in any medium, provided the original work is properly cited.

\section{ABSTRACT}

Background: Cardiac disease is a leading cause of maternal mortality and morbidity. Timely diagnosis and appropriate management can significantly improve the maternal and perinatal outcome.

Methods: This prospective observational study was performed over a period of 18 months at a tertiary care centre in Mumbai. A total of 100 women with heart disease were included in the study. The subjects were followed up during the antenatal, intrapartum and postpartum period to study the maternal and perinatal outcome.

Results: Out of 14791 confinements 100 consenting patients were included in the study. The incidence of heart disease came out to $0.9 \%$. Rheumatic heart disease (RHD) was seen more commonly as compared to congenital heart disease (CHD) and peripartum cardiomyopathy. 64\% patients delivered vaginally out of which $8 \%$ had instrumental delivery and 28\% underwent a lower segment caesarean section (LSCS). 21\% patients had cardiac complications like pulmonary edema, arrhythmias, sepsis, DIC etc. and there were 3 maternal mortalities. 58\% of the babies were born low birth weight, $90.9 \%$ of the babies had an Apgar score of $>7.60 \%$ of the babies were born at term whereas $26 \%$ had a preterm delivery.

Conclusions: Patients of cardiac disease with pregnancy need to be managed at a tertiary care centre by a multidisciplinary team of doctors. Early diagnosis of heart disease and stringent management of complication is of utmost importance. Vaginal delivery is favourable and LSCS should be performed for an obstetric indication. Maternal heart disease leads to an increased incidence of preterm delivery and hence a joint care of neonatologist is mandatory in managing these patients.

Keywords: CHD, Maternal heart disease, MS, Peripartum cardiomyopathy, RHD

\section{INTRODUCTION}

Pregnancy is a matter of joy for a woman and her family. Many a times it comes with its share of complications. One such dreaded condition is pregnancy in women suffering from heart disease. Previously, the high maternal mortality in cardiac patients who became pregnant prompted the assertion women with an abnormal heart should not become pregnant. ${ }^{1}$ This longstanding notion needs to be revised today. There has been a progressive and substantial reduction in maternal death and improved fetal outcome in pregnant women with heart disease since $1950 .^{2,3}$ Nevertheless, heart disease remains a leading cause of non-obstetric maternal death during pregnancy. ${ }^{4}$

Prevalence of heart disease in pregnancy is found to vary between $0.3-3.5 \%{ }^{5}$ Rheumatic heart disease (RHD), once the most common cause of valvular disease in the developed world, is still a common disease in the nonindustrialized region with $90 \%$ of all heart disorders in women of child-bearing age being of rheumatic origin. ${ }^{6}$ Progress in the medical and surgical management of patients with complex congenital heart disease (CHD) 
has resulted in an increase in the number of those reaching adulthood and childbearing age. CHD currently accounts for $10 \%$ to $20 \%$ of all cardiac diseases during pregnancy.

Cardiac lesions and pregnancy both may affect each other adversely. Joint care of obstetrician, cardiologist and anaesthetist, avoidance of complications that add to the burden on the heart and compliance of the patient and her family to regular follow up will go a long way in ensuring a safe outcome for mother and foetus.

\section{METHODS}

The present study is a prospective observational study; it was carried out at a tertiary care centre in Mumbai over a period of 18 months. All patients recruited in the study were acquainted with the purpose and methodology of the study.

The women were divided into three broad groups - RHD, CHD and miscellaneous. All the groups were subdivided into surgically corrected and non-corrected group. The CHD group was also classified into two categories - those with cyanotic and acyanotic lesions.

Following parameters were studied: type of cardiac disease, valve affected, socioeconomic status, obstetric history, associated obstetric complication, mode of delivery, medical/cardiac intervention, investigations and neonatal outcome.

The patients were regularly seen by an obstetrician at the antenatal clinic and by a cardiologist. They were thoroughly followed up during the antenatal, intrapartum and post-partum period. Relevant investigations were performed when needed. Complications were managed with the advice of cardiologists and intensivist in an ICU.

Patients who came for Medical termination of pregnancy or the patients in whom pregnancy if continued would pose grave risk to mother's life were sub grouped as the family planning group and MTP was offered to them.

\section{RESULTS}

Incidence of heart disease according to present study was $0.9 \%$.

Table 1: Type of heart disease.

\begin{tabular}{|lll|}
\hline Type of heart disease & Frequency & Percentage \\
\hline Congenital heart disease & 33 & 33.0 \\
\hline Rheumatic heart disease & 62 & 62.0 \\
\hline Miscellaneous & 5 & 5.0 \\
\hline Total & 100 & 100.0 \\
\hline
\end{tabular}

In present study $62 \%$ of the patients had Rheumatic heart disease, whereas congenital heart disease was seen in $33 \%$ of the patients. $5 \%$ of the patients had miscellaneous conditions like peripartum cardiomyopathy (4\%) and hypertrophic cardiomyopathy $(1 \%)$.

Table 2: Type of lesions in rheumatic heart disease.

\begin{tabular}{|lll|}
\hline Type of RHD & Frequency & Percentage \\
\hline Mitral stenosis & 41 & 41.0 \\
\hline Mitral regurgitation & 36 & 36.0 \\
\hline Aortic regurgitation & 13 & 13.0 \\
\hline Tricuspid regurgitation & 11 & 11.0 \\
\hline Aortic stenosis & 3 & 3.0 \\
\hline
\end{tabular}

The most commonly affected valve in present study was the mitral valve $(77 \%)$ (MS+MR). The most common lesion affecting the mitral valve was mitral stenosis, seen in $41 \%$ of the cases. This was closely followed by mitral regurgitation seen in $36 \%$ of the cases. Aortic valve was affected in $16 \%$ of the cases with aortic regurgitation and aortic stenosis seen in $13 \%$ and $3 \%$ of the patients respectively. Tricuspid valve was least involved with an incidence of $11 \%$, causing tricuspid regurgitation in the affected cases.

Table 3: Types of lesions in congenital heart disease.

\begin{tabular}{|lll|}
\hline Type of CHID & Frequency & Percentage \\
\hline Mitral valve prolapse & 8 & 8.0 \\
\hline Atrial septum defect & 8 & 8.0 \\
\hline Ventricular septum defect & 6 & 6.0 \\
\hline Tetralogy of Fallot & 4 & 4.0 \\
\hline $\begin{array}{l}\text { Transposition of great } \\
\text { arteries }\end{array}$ & 3 & 3.0 \\
\hline Pulmonary stenosis & 3 & 3.0 \\
\hline Bicuspid aortic valve & 2 & 2.0 \\
\hline Patent ductus arteriosus & 1 & 1.0 \\
\hline
\end{tabular}

Among the patients having congenital heart disease mitral valve prolapse (8\%) and atrial septum defect $(8 \%)$ were the two most common lesions. Ventricular septum defect was seen in $6 \%$ of the patients. $4 \%$ of the patients had tetralogy of Fallots. Pulmonary stenosis, Bicuspid aortic valve and Patent ductus arteriosus was seen in 3\%, $2 \%$ and $1 \%$ of the patients respectively.

Table 4: Socioeconomic status.

\begin{tabular}{|l|l|l|}
\hline Socioeconomic status & Frequency & Percentage \\
\hline Upper middle & 6 & 6.0 \\
\hline Lower Middle & 35 & 35.0 \\
\hline Upper lower & 19 & 19.0 \\
\hline Lower & 40 & 40.0 \\
\hline Total & 100 & 100.0 \\
\hline
\end{tabular}

Patients were divided into upper middle, lower middle, upper lower and lower socioeconomic strata according to Modified Kuppuswamy's criteria. Majority of the patients $(59 \%)$ belonged to the lower socioeconomic strata followed by the lower middle class $(35 \%)$. A small percentage of patients belonged to the upper middle class 
(6\%) that were transferred from private peripheral hospitals.

Table 5: Clinical presentation.

\begin{tabular}{|lll|}
\hline NYHA classification & Frequency & Percentage \\
\hline Class I & 66 & 66.0 \\
\hline Class II & 27 & 27.0 \\
\hline Class III & 7 & 7.0 \\
\hline Class IV & 0 & 0.0 \\
\hline Total & 100 & 100.0 \\
\hline
\end{tabular}

Patients were divided into the four NYHA classes based on the severity of symptoms at the time of presentation. $66 \%$ patients were grouped into class I as they had no limitations in the ordinary physical activity. 26\% belonged to class II and $7 \%$ to class III. Authors however did not have any patients presenting to us with severe limitation and having symptoms even at rest.

Table 6: Corrective surgery.

\begin{tabular}{|lll|}
\hline Corrective surgery & Frequency & Percentage \\
\hline Done & 34 & 34.0 \\
\hline Not done & 66 & 66.0 \\
\hline Total & 100 & 100.0 \\
\hline
\end{tabular}

In the present study $34 \%$ of the patients had corrective surgeries done for their cardiac conditions, either in the past or during their treatment at present institution. The rest $66 \%$ of patients did not require any surgical intervention.

Table 7: Cardiac complications.

\begin{tabular}{|lll|}
\hline Cardiac complications & Frequency & Percentage \\
\hline Pulmonary edema & 10 & 10.0 \\
\hline Congestive cardiac failure & 7 & 7.0 \\
\hline Atrial fibrillation & 4 & 4.0 \\
\hline
\end{tabular}

$21 \%$ patients in present study required ICU admission for various complications. The most common complications being pulmonary edema (10\%) followed by Congestive cardiac failure (7\%), and arrhythmias (4\%). Authors had a maternal mortality of $3 \%$.

Table 8: Obstetric risk factors.

\begin{tabular}{|lll|}
\hline Obstetric risk factors & Frequency & Percentage \\
\hline Anaemia & 4 & 4.0 \\
\hline Previous LSCS & 13 & 13.0 \\
\hline $\begin{array}{l}\text { Intra-uterine growth } \\
\text { retardation }\end{array}$ & 4 & 4.0 \\
\hline $\begin{array}{l}\text { Preeclampsia } \\
\text { Premature rupture of } \\
\text { membranes }\end{array}$ & 10 & 10.0 \\
\hline $\begin{array}{l}\text { Gestational diabetes } \\
\text { mellitus }\end{array}$ & 5 & 5.0 \\
\hline
\end{tabular}

The most common obstetric complication was found to be a history of previous caesarean section seen in $13 \%$ of patients, either alone or in association with other complications. $10 \%$ of the patients were diagnosed with preeclampsia. There was an association of gestational diabetes mellitus (GDM) in $6 \%$ of the patients. PROM complicated $5 \%$ of the pregnancies and $4 \%$ of patients had anaemia and IUGR each.

Table 9: Mode of delivery.

\begin{tabular}{|lll|}
\hline Mode of delivery & Frequency & Percentage \\
\hline Normal vaginal delivery & 56 & 56.0 \\
\hline $\begin{array}{l}\text { Lower segment } \\
\text { caesarean section }\end{array}$ & 28 & 28.0 \\
\hline $\begin{array}{l}\text { Instrumental delivery } \\
\text { Medical termination of } \\
\text { pregnancy }\end{array}$ & 8 & 8.0 \\
Check curettage & 5 & 5.0 \\
\hline Suction evacuation & 1 & 2.0 \\
\hline Total & 100 & 1.0 \\
\hline
\end{tabular}

Vaginal route is the preferred mode of delivery in patients with cardiac disease. $56 \%$ of present patients had a normal vaginal delivery, whereas $8 \%$ had assisted vaginal deliveries. $28 \%$ patients underwent LSCS, mostly for an obstetric indication. $5 \%$ of the patients chose to undergo Medical Termination of Pregnancy, $4 \%$ in the first trimester and $1 \%$ in the second trimester. $2 \%$ patients presented with incomplete abortion and had to undergo check curettage. 1 patient underwent suction evacuation for vesicular mole.

Table 10: Neonatal outcome.

\begin{tabular}{|lll|}
\hline Birth weight & Frequency & Percentage \\
\hline Normal & 30 & 30.0 \\
\hline Low Birth-weight & 58 & 58.0 \\
\hline
\end{tabular}

Most of the babies (58\%) were born low birth-weight (birth weight $<2500 \mathrm{~g}$ ). $30 \%$ of the babies had normal birth weight.

Table 11: Apgar score.

\begin{tabular}{|lll|}
\hline APGAR score & Frequency & Percent \\
\hline Mild depression (4-6) & 8 & 9.1 \\
\hline No depression (7-10) & 80 & 90.9 \\
\hline Total & 88 & 100.0 \\
\hline
\end{tabular}

$90 \%$ of the babies had a reassuring Apgar score of 7-10. $8 \%$ had a low Apgar score owing to preterm delivery or associated obstetric high-risk condition.

\section{DISCUSSION}

Cardiac disease continues to be a risk factor for maternal and neonatal mortality and morbidity. Despite advances 
in diagnosis and treatment, maternal heart disease represents an interdisciplinary medical challenge.

Incidence of heart disease in pregnancy varies from 0.3 $3.5 \%$ worldwide. $^{7,8}$ According to the present study the incidence of heart disease was $0.9 \%$. This was close to the study conducted by Bangal et al and Nagmani G et al where the incidences were $1.3 \%$ and $1.2 \%$ respectively. 9,10

There has been a relative decline in the incidence of rheumatic heart disease and rise in congenital heart disease, yet rheumatic heart disease is responsible for majority of the cases. The incidence of RHD was $62 \%$ in present study and that of CHD was $33 \%$. In a similar study by Hiralal $\mathrm{K}$ et al the principal cause of cardiac lesion was rheumatic heart disease $(69 \%)$ followed by congenital heart disease $(21 \%) .{ }^{11}$ In a study conducted in Brazil by Aliva et al the incidence of Rheumatic heart disease was $55.7 \%$ and that of congenital heart disease was $19.1 \% .^{12}$ The incidence of rheumatic heart disease in developed countries has been greatly reduced by the widespread use of antibiotics effective against the streptococcal bacterium which causes rheumatic fever. Thus, present study indirectly indicates inadequate treatment of girls suffering from streptococcal infection in their childhood and adolescence. Most of the patients in present study $(59 \%)$ belonged to the lower socioeconomic strata followed by the lower middle class (35\%). According to the study conducted by Hema et al
$70.8 \%$ belonged to the lower middle-class family. $66.7 \%$ patients hailed from rural area. $98.6 \%$ of these women were housewives. ${ }^{13}$

In present study patients were divided into the four NYHA classes based on the severity of symptoms at the time of presentation. $66 \%$ patients were grouped into class I, $26 \%$ to class II and $7 \%$ to class III. Authors did not have any patients in class IV. In a study by Konar et al $83.2 \%$ patients belonged to class I and II. $15 \%$ patients belonged to class III and $4 \%$ patients belonged to class IV. ${ }^{11}$ In another study by Nagamani et al $45 \%$ patients belonged to class I, $33.3 \%$ to class II, $6.6 \%$ to class III and $15 \%$ to class IV. ${ }^{10}$ This was antagonistic to present study where there were no patients in class IV.

Ideally cardiac surgery should be anticipatory and precede conception. The best period to undergo a cardiac surgery is $2^{\text {nd }}$ trimester after organogenesis is complete. $34 \%$ patients in present study underwent a corrective cardiac surgery. In the study by Indira et al $15 \%$ of RHD and $9 \%$ of CHD cases were surgically corrected. ${ }^{14}$ In the study by Hiralal K et al only $8 \%$ patients had undergone a corrective cardiac surgery. ${ }^{11}$ The results of study done by Nagamani et al were similar to ours where in $33 \%$ cases had undergone a corrective cardiac surgery.

In this cohort of patients, various obstetric and medical complications were seen, which are tabulated below along with the comparison with various studies. ${ }^{13-15}$

Table 12: Associated major obstetrics complication.

\begin{tabular}{|lllll|}
\hline Associated major obstetrics complication & Present study & Bhandiwad et al & Nqayana T et al & Bangal et al \\
\hline Anaemia & $4 \%$ & $4.1 \%$ & - & $16 \%$ \\
\hline Prev. LSCS & $13 \%$ & - & $6 \%$ & - \\
\hline IUGR & $4 \%$ & $2.7 \%$ & $2 \%$ & $2 \%$ \\
\hline Preeclampsia & $10 \%$ & $2.7 \%$ & $1 \%$ & $2 \%$ \\
\hline PROM & $5 \%$ & $1.3 \%$ & - & $8 \%$ \\
\hline GDM & $6 \%$ & $1.3 \%$ & - & - \\
\hline
\end{tabular}

In the present study $46 \%$ of the patients had a full-term delivery and $34 \%$ patients had a pre-term delivery. Out of the $62 \%$ patients that delivered vaginally $8 \%$ patients required instrumental delivery. $28 \%$ patients underwent lower segment caesarean section for obstetric indication. $4 \%$ of the patients went for first trimester Medical termination of pregnancy. $1 \%$ patient went for a second trimester Medical termination of pregnancy; Suction evacuation was performed for one patient with vesicular mole. In a similar study by Priya HL et al the $61 \%$ patients who delivered normally vaginally, $18 \%$ required instrumental delivery. $12 \%$ were outlet forceps and $6 \%$ vacuum extractions respectively. ${ }^{13}$ In the study by Bangal et al $(62.8 \%)$ patients delivered spontaneously vaginally at term and $(11 \%)$ delivered prematurely. There were
(20\%) cases of prophylactic forceps delivery. Caesarean section was performed in 2 cases. $^{9}$

In an African study by Nqayana $\mathrm{T}, 60 \%$ patients delivered at term and $26 \%$ had a pre-term delivery. $40 \%$ patients had a vaginal delivery and $55 \%$ patients had caesarean section. Out of the $55 \%$ caesarean sections $18 \%$ were emergencies and $37 \%$ were elective $\mathrm{C} / \mathrm{S} .^{15}$

In present study authors found a positive association between an obstetric high-risk condition with the mode of delivery. Patients who had an associated obstetric complication like previous caesarean section, preeclampsia or gestational diabetes mellitus had an increased rate of lower segment caesarean section. 
$21 \%$ patients in present study required ICU admission for various complications. The most common being pulmonary edema (10\%), followed by Congestive cardiac failure $(7 \%)$ and arrhythmias (4\%). Maternal mortality was $3 \%$. In the study by Priya HL et al worsening of NYHA status was seen in $5.5 \%$ of patients in the third trimester. Four patients went into cardiac failure and 6 developed atrial fibrillations.

Authors had a maternal mortality of 3\%, while the study by Nagamani et al had a maternal mortality of $5 \%$. Out of 3 cases, 2 cases were of severe mitral stenosis. In the study by Konar et al Cardiac failure was seen in $7.4 \%$ of the cases. $5.33 \%$ cases had sustained arrhythmia requiring therapy and 1 case was complicated by an embolism $(0.3 \%)$ Bacterial endocarditis was seen in 1 case $(0.3 \%)$. Maternal mortality was $1.1 \% .^{9}$

\section{CONCLUSION}

Patients of cardiac disease with pregnancy need to be managed at a tertiary care centre by a multidisciplinary team of doctors. Early diagnosis of heart disease and stringent management of complication is of utmost importance. Vaginal delivery is favourable and LSCS should be performed for an obstetric indication. Maternal heart disease leads to an increased incidence of preterm delivery and hence a joint care of neonatologist is mandatory in managing these patients.

\section{Funding: No funding sources}

Conflict of interest: None declared

Ethical approval: The study was approved by the Institutional Ethics Committee

\section{REFERENCES}

1. Launay D, Hachulla É. Cardiac and pulmonary scleroderma. Scleroderma. The Practitioner's Review. 2002;52(17):1901-7.

2. Silverman ME. A view from the millennium: The practice of cardiology circa 1950 and thereafter. J Am Coll Cardiol. 1999;33(5):1141-51.

3. Perloff JK. Systemic complications of cyanosis in adults with congenital heart disease. Hematologic derangements, renal function, and urate metabolism. Cardiol Clin. 1993;11(4):689-99.

4. Lewis G, Drife J, Clutton-Brock T. Maternal C into. Why Mothers Die: 2000-2002: the sixth report of the confidential enquiries into maternal deaths in the United Kingdom. RCOG. 2004.

5. WHO. Trends in Mternal Mortality: 1990-2013. Estimates by WHO, UNICEF, UNFPA, The World Bank and the United Nations Population Division. World Heal Organ. 2014;56.

6. Puri S, Bharti A, Puri S, Mohan B, Bindal V, Verma S. Maternal heart disease and pregnancy outcomes. J Med Educ Res. 2013;15(1):7-10.

7. Sugrue D, Blake S, MacDonald D. Pregnancy complicated by maternal heart disease at the National Maternity Hospital, Dublin, Ireland, 1969 to 1978. Am J Obs Gynecol. 1981;139(1):1-6.

8. McFAUL PB, Dornan JC, Lamki H, Boyle D. Pregnancy complicated by maternal heart disease. A review of 519 women. BJOG: An Int J Obstet Gynaecol. 1988;95(9):861-7.

9. Bangal VB, Singh RK, Shinde KK. Clinical study of heart disease complicating pregnancy. J Pharma. 2012;2(4):25-8.

10. Nagamani G, Bhavani K, Isukapalli V, Lagudu S. Heart disease in pregnancy prospective study from southern India. Int J Current Med App Sci. 2015;6(1):8-12.

11. Hiralal K, Snehamay C. Pregnancy complicated by maternal heart disease: A review of 281 women. $\mathbf{J}$ Obstet Gynecol India. 2012;62(3):301-6.

12. Avila WS, Rossi EG, Ramires JA, Grinberg M, Bortolotto MR, Zugaib M, et al. Pregnancy in patients with heart disease: experience with 1,000 cases. Clin Cardiol. 2003;26(3):135-42.

13. Bhandiwad A, Desai N, Kondareddy T. Maternal outcomes of rheumatic heart disease in pregnancy. Int J Reprod Contracept Obstet Gynecol. 2017;6(3):802-6.

14. Indira I, Sunitha K, Professor JA, Professor AP, Gynecologist CO. Study of pregnancy outcome in maternal heart disease. IOSR J Dent Med Sci Ver IV. 2015;14(7):2279-861.

15. Nqayana T, Moodley J, Naidoo DP. Cardiac disease in pregnancy. Cardiovasc J Afr. 2008;19(3):145-51.

Cite this article as: Kamble PD, Bava AK. A study of pregnancy outcome in patients with cardiac disease. Int J Reprod Contracept Obstet Gynecol 2018;7:5111-5. 